\title{
Compartmentation of storage compounds in peach leaves
}

\author{
J.P. Gaudillère ${ }^{1}$, A. Moing ${ }^{1}$, A. Lamant ${ }^{2}$, M. Brison ${ }^{2}$ and \\ J. Schaeffer ${ }^{2}$
}

1Station de Physiologie Végétale, INRA, Centre de Bordeaux, BF 131, 33140 Pont-de-la-Maye, and

2Laboratoire de Biologie et de Physiologie Végétale, CNRS UA568, Université de Bordeaux I, 33405 Talence Cedex, France

\section{Introduction}

High leaf photosynthesis is achieved when primary photosynthetic products are actively metabolized to avoid inhibition of the carbon reduction cycle. Two main conditions must be fulfilled: 1) mineral phosphate must be available (Sivak and Walker, 1986); and 2) osmotic pressure must be regulated at a physiological level (Kaiser et al., 1981). Many strategies are found amount plants. Carbon can be stored as starch in the chloroplast. Sucrose can be stored in the vacuole and soluble polysaccharides can be synthesized as fructans. Sugar transfer from the mesophyll cells can be very efficient. It can fill storage compartments in the leaf or be loaded into the phloem and exported to other parts of the plant. The study of interactions between photosynthesis and sink activity (growth and storage) requires detailed information about the movement of carbon among different chemical fractions and among different cell types of the leaf. In this way, we examined the distribution of carbon in peach leaves.

\section{Materials and Methods}

\section{Plant material}

Green or red seedlings of Prunus persica $L$. Batsch (var. 'GF305', green; var. 'Rubira', red) were grown in a growth chamber (15 $\mathrm{h}$ photoperiod, high pressure $\mathrm{Na}$ lamps $(800$ $\mu \mathrm{M} \cdot \mathrm{m}^{-2} \cdot \mathrm{s}^{-1}$ and $25 / 20^{\circ} \mathrm{C}$ day-night temperafure). For protoplast preparation, expanding leaves (about $25 \%$ of final area) were collected $5 \mathrm{~h}$ after the beginning of the light period. The first mature leaves used for sugar analysis were collected at the beginning and at the end of the light period.

\section{Biochemical analyses}

Glucose, sucrose, sorbitol, inositol and a cyanogenic glucoside, prumasin, were extracted with hot $\left(60^{\circ} \mathrm{C}\right)$ ethanol/water $(1 / 1, v / v)$ and analyzed by gas-liquid chromatography (Moing et al., 1988). Starch was assayed enzymatically (Boehringer, Mannheim). In situ starch was located by iodine staining in intact leaves bleached with $\mathrm{N}, \mathrm{N}$-dimethylformamide.

\section{Preparation and purification of protoplasts}

The partially expanded leaves were harvested and surface sterilized. Main veins were removed. Leaf strips were put into the digestion medium and incubated for $15 \mathrm{~h}$ and $25^{\circ} \mathrm{C}$ on a 
gyratory shaker (Ochatt et al., 1987). The partially digested leaves were filtered through a nylon net $(26 \mu \mathrm{m})$. Protoplasts were purified on a Percoll gradient (Robinson and Loveys, 1986), after staining of the vacuoles with neutral red for protoplasts prepared from green leaves. Large protoplasts were collected at the $80 / 60 \%$ Ficoll interface; small protoplasts bearing chlorophyll were collected at the 50/30\% Percoll interface.

\section{Results}

Chemical characterization of storage compounds in mature peach leaves

The quantitatively most important compounds of adult peach leaves are presented in Table I. These compounds represented about $40 \%$ of the total leaf dry weight at the end of the light period. Compounds which significantly decreased in concentration during the night, have a storage function. Starch and sorbitol were the main carbon storage compounds in these leaves. Sucrose concentration also decreased during the night but to a lesser extent. The other surveyed compounds had no storage function during this time.

\section{Distribution of storage compounds inside a growing leaf}

In growing leaf tissue after $5 \mathrm{~h}$ of light, the same chemical fractions as in mature leaf tissue were present (Table II).
The preparation of protoplasts resulted in 2 main cell types. The smaller protoplasts (diam. $\leq 10 \mu \mathrm{m}$ ) came from mesophyll tissue, as they contained chlorophyll pigments. They were poorly vacuolated and had large starch granules in chloroplasts. The large protoplasts (diam. $\approx 20$ $\mu \mathrm{m})$ came from epiderm, as they contained anthocyanin pigments if they were isolated from the red peach seedlings. Anthocyanin pigments are typically localized in leaf epiderm (Thayer and Conn, 1981). Microscopic observation did not reveal chloroplasts or amyloplasts. Prunasin was exclusively contained in epidermal cells (Table III). Conversely, inositol was found in mesophyll cells. Sucrose was mainly accumulated in epidermal cells and sorbitol in mesophyll cells. The number of epidermal cells relative to mesophyll cells was estimated to be $13 \%$ by counting on leaf cross-sections. Based on this percentage, it was possible to calculate the relative amount of storage compounds between epiderm and mesophyll (Table IV). Sucrose and prunasin accumulated in epidermal cells, while starch seemed to be equally distributed. This last result was surprising because electron microscopic observation did not reveal a significant amount of starch in large protoplasts. This cell fraction might have been contaminated by free starch grains liberated during leaf digestion. By electron microscopy, we observed large lipid deposition in both types of cells. But is was not possible to quantify specifically this carbon compartment.

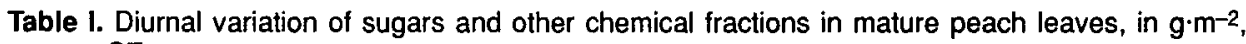
mean \pm SE.

\begin{tabular}{lllllll}
\hline & Glucose & Sucrose & Sorbitol & Inositol & Prunasin & Starch \\
\hline End of day & $0.36 \pm 0.06$ & $1.41 \pm 0.13$ & $3.62 \pm 0.36$ & $0.13 \pm 0.02$ & $0.35 \pm 0.09$ & $9.26 \pm 1.11$ \\
End of night & $0.42 \pm 0.10$ & $0.68 \pm 0.09$ & $1.61 \pm 0.21$ & $0.17 \pm 0.03$ & $0.57 \pm 0.15$ & $4.52 \pm 0.76$ \\
\hline
\end{tabular}


Table II. Chemical fractions of one expanding peach leaf after $5 \mathrm{~h}$ of illumination $(\mathrm{g} \cdot \mathrm{m}-2)$.

\begin{tabular}{llllll}
\hline & Sucrose & Sorbitol & Inositol & Prunasin & Starch \\
\hline Expanding leaf & 0.81 & 2.20 & 2.40 & 1.90 & 0.91 \\
\hline
\end{tabular}

Table III. Chemical fractions in small and large protoplasts purified from expanding peach leaves (pg.protoplast ${ }^{-1}$ ), mean \pm SE.

\begin{tabular}{llclllc}
\hline & Glucose & Sucrose & Sorbitol & Inositol & Prunasin & Starch \\
\hline Small & $10.2 \pm 4.5$ & $1.0 \pm 0.6$ & $7.3 \pm 4.6$ & $2.8 \pm 1.3$ & 0 & $5.6 \pm 1.7$ \\
Large & $32 \pm 11$ & $16 \pm 11$ & $4.1 \pm 2.2$ & trace & $253 \pm 72$ & $34 \pm 10$ \\
\hline
\end{tabular}

Table IV. Percentage of different chemical fractions stored in epidermal cells of expanding peach leaves ( $25 \%$ of final area).

\begin{tabular}{lllllll}
\hline & Glucose & Sucrose & Sorbitol & Inositol & Prunasin Starch \\
\hline$\%$ & 35 & 71 & 13 & 0 & 100 & 58 \\
\hline
\end{tabular}

The iodine starch staining of intact leaves showed that bundlesheath cells stored a large amount of starch which was not taken into account in our analysis.

\section{Conclusions}

In photosynthetic cells, carbon can be stored as sorbitol, starch and lipids. Carbon can be exported to epiderm and stored as prunasin, sorbitol, sucrose and lipids or to the bundlesheath and stored mainly as starch. Prunasin, mainly stored in peach leaf epiderm, like dhurrin in sorghum leaf epiderm (Thayer and Conn, 1981), decreases in concentration during leaf growth. It is probably reassimilated as in seedlings of Hevea (Selmar et al., 1988). Lastly, carbon can be exported by phloem loading and translocated as sorbitol. The modelling of the distribution of carbon in these leaves is a difficult task. It must consider the size and the turnover of all these compartments.

\section{References}

Butt A.D. (1985) A general method for the high yield isolation of mesophyll protoplasts from deciduous tree species. Plant Sci. 42, 55-59

Kaiser W.M., Kaiser G., Prachuab P.K., Wildman S.G. \& Heber U. (1981) Photosynthesis under osmotic stress. Inhibition of photosynthesis of intact chloroplasts, protoplasts and leaf slices at high osmotic potential. Planta 153, 416.422

Matile P. (1987) The sap of plant cells. New Phytol. 105, 1-26

Moing A., Salesses G. \& Saglio P.H. (1987) Growth and the composition and transport of 
carbohydrate in compatible and incompatible peach/plum grafts. Tree Physiol. 3, 345-354

Ochatt S.J., Cocking E.C. \& Power J.B. (1987) isolation, culture and plant regeneration of colt cherry (Prunus avium x laurocerasus) protoplasts. Planta 50, 139-143

Robinson S.P. \& Loveys B.R. (1986) Uptake and retention of external solutes from the digest medium during preparation of protoplasts. Plant Sci. 46, 43-51
Selmar D.R., Lieberei R. \& Biehl B. (1988) Mobilization and utilization of cyanogenic glycosides. Plant Physiol. 86, 711-716

Sivak M.N. \& Walker D.A. (1986) Photosynthesis in vivo can be limited by phosphate supply. New Phytol. 102, 499-512

Thayer S.S. \& Conn E.E. (1981) Subcellular localization of dhurrin $\beta$-glucosidase and hydroxynitrile lyase in the mesophyll cells of sorghum leaf blades. Plant Physiol. 67, 617-622 